\title{
Statin use and prostate cancer risk in a large population-based setting
}

\author{
Denise M. Boudreau ${ }^{1,2}$, Onchee $\mathbf{Y u}^{1}$, Diana S. M. Buist ${ }^{1,2}$, and Diana L. Miglioretti ${ }^{1,2}$ \\ 1 Group Health Center for Health Studies, 1730 Minor Ave., Suite 1600, Seattle, WA 98101, USA, e-mail: \\ boudreau.d@ghc.org \\ 2 University of Washington, Seattle, WA, USA
}

\begin{abstract}
Background-Statins are a commonly used cholesterol-lowering drug, which also have the potential to affect cancer risk and progression. Results from previous studies offer mixed conclusions.

Methods-To evaluate the relation between statin use and prostate cancer risk, we conducted a retrospective cohort study during 1 January 1990 to 31 August 2005 among men 45-79 years receiving care within Group Health, an integrated healthcare delivery system. Information on statin use and covariates were obtained from health plan databases. We identified incident prostate cancer cases through the Surveillance, Epidemiology, and End Results cancer registry. We used Cox proportional hazards models to estimate the hazard ratios (HR) and 95\% confidence intervals (CI) for prostate cancer among statin users compared to non-users.
\end{abstract}

Results-Among 83,372 men studied, median follow-up time was 5.7 years and 2,532 prostate cancer cases were identified. About $14.4 \%$ used statins over the study period and median duration of use was 3.3 years. Compared to non-users, hydrophobic statin users had a reduced risk of prostate cancer $(\mathrm{HR}=0.79 ; 95 \% \mathrm{CI}, 0.66-0.94)$, and results are suggestive of a reduced risk among ever users of statins ( $\mathrm{HR}=0.88 ; 95 \% \mathrm{CI}, 0.76-1.02)$ and hydrophilic statin users $(\mathrm{HR}=0.67 ; 95 \% \mathrm{CI}$, $0.33-1.34)$. There was no trend in risk by duration of statin use, and no association between statin use and cancer aggressiveness, stage, or grade.

Conclusion-Overall, this study does not support an associated between statin use and prostate cancer but a reduced risk cannot be ruled out.

\section{Keywords}

Statins; Prostate cancer; Lipid lowering drugs; HMG-CoA reductase inhibitors; Cancer

\section{Introduction}

Prostate cancer is the second most common cancer among men in the US [1]. In 2007, approximately 219,000 new cases of prostate cancer will be diagnosed and 27,000 deaths will occur from this disease [1]. HMG-CoA inhibitors (statins) reduce plasma cholesterol levels and are used to manage and prevent coronary heart disease [2]. Introduced in 1987, statins are one of the most commonly prescribed drugs in the US [3], and a growing body of laboratory studies suggests statins may have chemopreventive potential against cancer [4,5]. Statins have been shown to inhibit tumor initiation, growth, and metastasis of tumor cells [5]. This suspected anticancer effect is biologically plausible because statins inhibit many of the products of the 
mevalonate pathway that are necessary for critical cellular functions such as membrane integrity, cell signaling, protein synthesis, and cell cycle progression [6].

Results from epidemiologic studies of statin use and prostate cancer risk vary, with some reporting either no overall effect on risk [7-13] or a decrease in risk [14-17]. Only one epidemiologic study found a moderate increase in risk [18]. However, recent studies consistently report that statins reduce advanced and metastatic/fatal prostate cancer [9-11,19, 20], and aggressive disease [14]. Clinical trials of statin use and cardiovascular endpoints have generally not found an altered risk of overall cancer or site-specific cancers with statin use [21], but long-term follow-up of the West of Scotland Coronary Prevention Study recently reported a trend toward an increased risk of prostate cancer among the pravastatin group compared with placebo [22]. Meta-analyses of trials and meta-analyses of trials and epidemiologic studies combined do not support an association between statin use and reduced cancer risk [21,23-28]. All results should be considered, but the trials were not powered to assess rare safety outcomes such as cancer and follow-up periods were relatively short compared to the long latency period of cancer.

To address the mixed results, we examined the association between statin use and prostate cancer risk, including aggressive disease, stage, and tumor grade using a prospective design in a large population-based setting that does not regularly screen for prostate cancer (i.e., reducing the influence of detection bias). We previously published results on the association between statin use and breast cancer risk using a similar methodology as described below [29].

\section{Methods}

\section{Study population}

We conducted a dynamic retrospective cohort study among men enrolled in Group Health, a non-profit integrated delivery system that provides comprehensive health care on a pre-paid basis to approximately 550,000 individuals throughout western Washington State. Group Health's Institutional Review Board approved the study.

Men were included in the study if they met all the following criteria: (1) continuously enrolled in Group Health's integrated group practice for at least two years during the study period of 1 January 1990 to 31 August 2005; (2) between the age of 45-79 years anytime during the study period; (3) residing in 1 of 13 Washington counties covered by the western Washington Surveillance, Epidemiology, and End Results (SEER) cancer registry, and (4) no prior history of prostate cancer as identified in the SEER registry.

\section{Data collection}

We used automated health plan data to ascertain information on medication use and potential confounders. Information on enrollment, health care utilization including medication use, diagnoses, and laboratory results are recorded and maintained in Group Health's automated databases that can be linked by a unique consumer number [30]. Group Health automated pharmacy data are considered a complete source of medication use; enrollees obtain approximately $97 \%$ of their medications at Group Health pharmacies [31,32]. Computer linkage between active Group Health enrollees and the SEER registry provides near complete ascertainment of cancer cases [33]. Similarly, Washington State Death records for active enrollees are regularly obtained [34].

\section{Statin use}

Using the Group Health automated pharmacy database, we identified all statins (atorvastatin, cerivastatin, lovastatin, fluvastatin, pravastatin, simvastatin, and rosuvastatin) dispensed 
during the study period. For each statin dispensing, we estimated when the pills should have run out (run-out date) based on directions for use and quantity dispensed. A new run-out date was set with each successive dispensing. A 60-day lag period between the run-out date of one dispensing and fill date of the successive dispensing was used to define continuous use. Periods of continuous use were summed for total duration of use.

Statin users were defined as men with $2+$ dispensings for a statin within any six-month period and who used statins for at least one year. Men with 1 or less statin dispensing or less than one year of statin use were considered non-users. We considered men current users if statins were used within the previous 12 months and past users if statins were used more than 12 months prior. Among statin users, we calculated the cumulative lengths of statin use. Cumulative duration of statin use was categorized as 1-2.9, 3-4.9, and 5+ years. Statin use was further categorized as hydrophobic only users (lovastatin, simvastatin, fluvastatin, atorvastatin, and cerivastatin) or hydrophilic only users (pravastatin and rosuvastatin).

\section{Prostate cancer}

We identified all incident, invasive prostate cancer cases from the SEER registry. Aggressive disease was defined as prostate cancer diagnosed with grade 3 and a Gleason score between 8 and 10 , grade 4 , or regional or distant SEER summary stage. We also considered grade and stage separately and defined high-grade cancer as grade 3 and Gleason score between 8 and 10 or grade 4 . Advanced stage cancer was defined as regional or distant stage.

\section{Covariates}

We used outpatient, inpatient, laboratory, pharmacy, and administrative databases to identify potential confounders. Men meeting at least one of the following during Group Health enrollment were considered to have diabetes: (1) 2+ dispensings for a medication used to treat diabetes (e.g., sulfonylurea, insulin), (2) a fasting glucose $>125 \mathrm{mg} / \mathrm{dl}$ confirmed by a second out-of-range test within one year, (3) a random glucose $>200 \mathrm{mg} / \mathrm{dl}$ confirmed by a second test within one year, or (4) a hospital discharge of diabetes or at least two outpatient diagnosis of diabetes (ICD-9 codes of 250, 250.0, 250.1, 250.2, 250.3, 250.4, 250.5, 250.6, 250.7, 250.8, 250.9) at any time during Group Health enrollment [35]. Other lipid lowering drug use was defined as $2+$ dispensings of bile acid sequestrants, niacin, or fibrates. Non-steroidal antiinflammatory drug (NSAID) use was defined as 2+ dispensings of NSAIDS including cyclooxygenase II selective inhibitors and aspirin-containing products. Hypercholesterolemia was defined as low-density lipoprotein $\geq 160 \mathrm{mg} / \mathrm{dl}$ or total cholesterol $\geq 240 \mathrm{mg} / \mathrm{dl}$.

\section{Statistical analysis}

Follow-up of the study cohort extended from 1 January 1991 or one year after enrollment in Group Health if later than 1 January 1990 until the earliest of the following: diagnosis of an incident invasive prostate cancer, 80 years of age, death, disenrollment from Group Health, or the end of the study period (31 August 2005). We used Cox proportional hazards models [36] to examine the association between statin use and risk of prostate cancer, prostate cancer aggressiveness, grade, and stage.

Statin use was modeled as a time-varying exposure. Subjects were allowed to transition from being non-users to users or from non-users to current users to past users over time. For analyses of statin type (hydrophobic or hydrophilic), $12.4 \%$ of users were censored when they began using a different type of statin. We adjusted the final models for age at the beginning of the study period and time-varying covariates for diabetes, other lipid lowering medication use, NSAID use, and hypercholesterolemia. We used a cubic smoothing spline [37] with five knots to model age. Cubic smoothing splines provide a flexible approach for modeling the non-linear relations between cancer risk and age to more completely adjust for confounding [37]. The 
proportional hazards assumption was evaluated by testing for the interaction of statin use with follow-up time. The assumption was met in all models. Analyses were performed using the SAS statistical package, version 9.1 (Cary, NC).

In a subgroup of men who were enrolled in Group Health for at least five years during the study period, we evaluated the relation between duration of statin use (1-2.9, 3-4.9, and 5+ years) and prostate cancer risk. Follow-up began on 1 January 1995 or five years after enrollment in Group Health if enrollment occurred after 1 January 1990. Men who died or developed prostate cancer during the first five years of the study period were excluded.

In sensitivity analyses, we only considered the true non-users of statins in the comparison group by excluding men with either one dispensing for a statin or use of less than one year. We also conducted subset analyses limited to men with at least one prostate specific antigen (PSA) test in the study period. However, Group Health follows the US Preventive Services Task Force guidelines [38] and does not recommend for or against routine screening for prostate cancer using PSA testing or digital rectal examination. Among men who were tested, we were unable to determine if PSA testing was for screening or diagnostic purposes.

\section{Results}

A total of 578,885 person-years were contributed by the 83,372 study cohort members. About $14.4 \%$ used statins for at least one year during the study period for a total of 44,906 personyears of statin use. Statin use increased steadily from $0.8 \%$ in 1991 to $31.1 \%$ in the first half of 2005 (Fig. 1), and the median cumulative duration of statin use during the study period was 3.3 years (range, $1-15.9$ years). The majority of statin use was hydrophobic (85.9\%). Lovastatin and simvastatin were the most commonly used statins and specific statin use varied by calendar year due to changes in the Group Health drug formulary.

Statin users were more likely to have a PSA test, diabetes, and hypercholesterolemia than nonusers (Table 1). Compared to non-users, statin users had higher rates of outpatient care visits (e.g., primary care, specialty care), other lipid lowering medication use, and NSAID use. We identified 2,532 prostate cancer cases during study follow-up. Cases were older than diseasefree men. Compared to disease-free men, we observed a higher frequency of PSA testing, outpatient visits, high cholesterol, and other lipid lowering medication use among prostate cancer cases. Cases were less likely to have diabetes than disease-free men. The majority of prostate cancer cases were diagnosed at American Joint Committee on Cancer (AJCC) stage $2(71.6 \%)$, grade 2 or moderately differentiated $(60.9 \%)$, and localized SEER summary stage (79.1\%). Per our definitions, $740(29.2 \%)$ of the prostate cancers were classified as aggressive tumors, $456(18.0 \%)$ high grade, and $458(18.0 \%)$ advanced stage. There was no difference in cancer characteristics (AJCC stage, SEER stage, aggressive tumor) by statin use except grade 1 (well differentiated tumors) were more prevalent among non-users (11.5\%) than users $(3.7 \%)$.

The median length of study follow-up was 5.7 years (range, 1 day to 14.7 years). From multivariable models, the results suggest a reduced risk of prostate cancer among ever users of statins (hazard ratio $(\mathrm{HR})=0.88 ; 95 \%$ confidence interval $(\mathrm{CI}), 0.76-1.02)$ compared with non-users but the difference was not statistically significant (Table 2). Compared to non-users, hydrophobic statin users had a reduced risk of prostate cancer (HR $=0.79$; 95\% CI, 0.66-0.94). While the point estimate for hydrophilic statin users also suggested a reduced risk of prostate cancer compared to non-users ( $\mathrm{HR}=0.67 ; 95 \% \mathrm{CI}, 0.33-1.34$ ), the confidence intervals were wide due to the low prevalence of hydrophilic statin use at Group Health. Among men enrolled in Group Health for at least five years during the study period, evaluation of the risk of prostate cancer by duration of statin use and duration of hydrophobic statin use revealed no significant 
trend. There was, however, a reduced risk of prostate cancer among the shortest duration of use category of $1-2.9$ years of statin use $(\mathrm{HR}=0.75 ; 95 \% \mathrm{CI}, 0.59-0.95$ for any statins and $0.74 ; 95 \%$ CI, $0.57-0.95$ for hydrophobic statins). We found no association between statin use and risk of more aggressive prostate cancer, high grade, or advanced stage (Table 3).

In sensitivity analyses, where only the true non-users of statin were included in the comparison group, the results remained the same. We observed trivial changes in results when analyses were limited to men with a PSA test during the study period, but the HR approached significance (HR $=0.86 ; 95 \% \mathrm{CI}, 0.74-1.00)$ for ever use of statins compared to non-users.

\section{Discussion}

The overall results of this population-based cohort study do not support an association between statin use and prostate cancer risk. While some point estimates suggest a reduced risk of prostate cancer among statin users compared to non-users, only hydrophobic statin use and ever use limited to men with a PSA test were statistically significant, and we did not observe a trend with duration of statin use. Point estimates do not suggest a difference in risk by type (hydrophobic versus hydrophilic) of statin use.

This was one of the few large cohort studies conducted in an integrated practice setting where men receive almost all their care within the system, and information on medication use and diagnoses are available. Other strengths of the study include the stability of the population over time, extensive and unbiased data on medication use and covariates, ability to look at hydrophobic statin use, and reliable data on cancer incidence. Our large population-based cohort demonstrates the dramatic increase in statin use over the past decade, which is consistent with the trend of statin use in the United States.

While we found some suggestion of a reduced risk but overall not statistically significant, it is biologically plausible that statins reduce prostate cancer risk. The mechanistic data is relatively strong and suggests statins inhibit cancer cell growth and lead to apoptotic cell death through their inhibition of the mevalonate pathway, although other mechanisms have also been suggested $[4,17]$. Many products of the mevalonate pathway are necessary for critical cellular functions such as membrane integrity, cell signaling, protein synthesis, and cell cycle progression [4,5]. Disruptions of these processes in neoplastic cells by statins may result in control of tumor initiation, growth, and metastasis [5]. Our results on type of statin also support evolving evidence that hydrophobic statins have antiproliferative effects on certain cancer cells [39-41]. It has been suggested that hydrophilic statins promote cancer [39], but our results suggest an inverse association between hydrophilic statin use and prostate cancer risk.

There are several limitations in our study. First, study subjects were from a single healthcare system in western Washington State and may not represent other populations. Second, we cannot rule out exposure misclassification. Subjects who fill prescriptions but do not subsequently take the medication may be misclassified as users. Additionally, pharmacy utilization is only captured for enrollees who fill prescriptions at Group Health pharmacies and for enrollees with a drug benefit through Group Health who fill prescriptions at contracting pharmacies. Therefore, subjects who fill prescriptions at non-Group Health pharmacies may be erroneously classified as non-users. However, mis-classification of medication use is relatively unlikely since previous Group Health studies have found that enrollees obtain 97\% of their medications at Group Health pharmacies [31,32], and we required 2+ dispensings and a year of use to be considered a statin user. We did not have information on medication use before enrollment in Group Health. While unlikely, misclassifying a user as a non-user could bias our findings toward the null and partly explain why we did not find a significant association between statin use and prostate cancer risk. Last, residual confounding is always possible. We 
lacked information on potential confounders such as body mass index, diet, socioeconomic status, and race, and men prescribed and adherent to statins may differ from non-users by factors not measured in this study. Statin users had more PSA testing and medical visits compared to non-users, which could lead to earlier detection of prostate cancer and bias results away from finding any true chemopreventive effect. However, results were similar when we limited our analyses to men with at least one PSA test during the study period. While not an aim of this study, there is also preliminary evidence to suggest that statin use may be associated with a decrease in PSA levels [42]. If such an association exists, prostate cancers could be missed when using PSA testing to screen for prostate cancer among statin users. Missed cases could lead to false conclusions that statins are associated with a reduced risk of prostate cancer but may later appear to be associated with an increased risk of advanced disease.

In conclusion, our study and other epidemiologic studies indicate that statins are safe in relation to prostate cancer risk but any chemopreventive effect remains to be established and recent report of increased prostate cancer risk with pravastatin use from the long-term follow-up of the West of Scotland Coronary Prevention Study are concerning [22]. To make conclusions about the effect of statins on prostate cancer prevention, mechanistic data suggests that the type, dose, and potency of statin used and the serum concentrations achieved need to be considered in observational studies $[39,43]$. We agree with Platz that the promising and consistent findings from the most recently published studies are remarkable [44], but many of the specifics on statin use (e.g., individual statins, potency) have not been adequately addressed, and the influence of detection bias [44] as well as other confounders such as socioeconomic status need further study. The research and clinical community must make decisions about whether further evaluation is warranted and, if so, what types of studies are needed. The evidence must be strong before any drug should be used to prevent disease in a healthy population.

\section{Acknowledgements}

We thank Deborah Seger, Dawn Fitzgibbons, Janet Stanford, and Ilir Agalliu for their valuable contributions. This study was supported by the National Cancer Institute (CA108357).

\section{References}

1. National Cancer Institute SEER cancer statistics review. Bethesda: [Accessed August 23, 2007]. Available: http://seer.cancer.gov/csr/1975_2001

2. Sewester, CS.; Dombek, CE.; Olin, BR.; Kastrup, EK.; Hebel, SK. Drug facts and comparisons. Wolters Kluwer Health; St. Louis: 2004.

3. The Top 200 Prescriptions for 2004 by U.S. Sales. RX List. [Accessed May 10, 2005]. Available at: http://www.rxlist.com/top200_sales_2004

4. Wong WW, Dimitroulakos J, Minden MD, Penn LZ. HMG-CoA reductase inhibitors and the malignant cell: the statin family of drugs as triggers of tumor-specific apoptosis. Leukemia 2002;16:508-519. [PubMed: 11960327]

5. Chan KK, Oza AM, Siu LL. The statins as anticancer agents. Clin Cancer Res 2003;9:10-19. [PubMed: 12538446]

6. Goldstraw MA, Amoroso P, Kirby RS. Do statins protect against prostate cancer? BJU Int 2006;97:1147-1148. [PubMed: 16686701]

7. Olsen JH, Johansen C, Sorensen HT, McLaughlin JK, Mellemkjaer L, Steffensen FH, et al. Lipidlowering medication and risk of cancer. J Clin Epidemiol 1999;52:167-169. [PubMed: 10201659]

8. Coogan PF, Rosenberg L, Strom BL. Statin use and the risk of 10 cancers. Epidemiology 2007;18:213219. [PubMed: 17235211]

9. Murtola TJ, Tammela TL, Lahtela J, Auvinen A. Cholesterol-lowering drugs and prostate cancer risk: a population-based case-control study. Cancer Epidemiol Biomarkers Prev 2007;16:2226-2232. [PubMed: 18006910] 
10. Jacobs EJ, Rodriguez C, Bain EB, Wang Y, Thun MJ, Calle EE. Cholesterol-lowering drugs and advanced prostate cancer incidence in a large U.S. cohort. Cancer Epidemiol Biomarkers Prev 2007;16:2213-2217. [PubMed: 17971518]

11. Platz EA, Leitzmann MF, Visvanathan K, Rimm EB, Stampfer MJ, Willett WC, et al. Statin drugs and risk of advanced prostate cancer. J Natl Cancer Inst 2006;98:1819-1825. [PubMed: 17179483]

12. Blais L, Desgagne A, LeLorier J. 3-Hydroxy-3-methyl-glutaryl coenzyme A reductase inhibitors and the risk of cancer: a nested case-control study. Arch Intern Med 2000;160:2363-2368. [PubMed: 10927735]

13. Coogan PF, Rosenberg L, Palmer JR, Strom BL, Zauber AG, Shapiro S. Statin use and the risk of breast and prostate cancer. Epidemiology 2002;13:262-267. [PubMed: 11964926]

14. Shannon J, Tewoderos S, Garzotto M, Beer TM, Derenick R, Palma A, et al. Statins and prostate cancer risk: a case-control study. Am J Epidemiol 2005;162:318-325. [PubMed: 16014776]

15. Flick ED, Habel LA, Chan KA, Van Den Eeden SK, Quinn VP, Haque R, et al. Statin use and risk of prostate cancer in the California men's health study cohort. Cancer Epidemiol Biomarkers Prev 2007;16:2218-2225. [PubMed: 17971519]

16. Singal R, Khurana V, Caldito G, Fort C. Statins and prostate cancer risk: a large case-control study in veterans. J Clin Oncol, 2005 ASCO Annual Meeting Proceedings 2005;23:1004.

17. Graaf MR, Beiderbeck AB, Egberts AC, Richel DJ, Guchelaar HJ. The risk of cancer in users of statins. J Clin Oncol 2004;22:2388-2394. [PubMed: 15197200]

18. Kaye JA, Jick H. Statin use and cancer risk in the general practice research database. Br J Cancer 2004;90:635-637. [PubMed: 14760377]

19. Moyad MA, Merrick GS, Butler WM, Wallner KE, Galbreath RW, Kurko B, et al. Statins, especially atorvastatin, may favorably influence clinical presentation and biochemical progression-free survival after brachytherapy for clinically localized prostate cancer. Urology 2005;66:1150-1154. [PubMed: 16360430]

20. Moyad MA, Merrick GS, Butler WM, Wallner KE, Galbreath RW, Butler EG, et al. Statins, especially atorvastatin, may improve survival following brachytherapy for clinically localized prostate cancer. Urol Nurs 2006;26:298-303. [PubMed: 16939047]

21. Browning DR, Martin RM. Statins and risk of cancer: a systematic review and metaanalysis. Int J Cancer 2007;120:833-843. [PubMed: 17131313]

22. Ford I, Murray H, Packard CJ, Shepherd J, Macfarlane PW, Cobbe SM. Long-term follow-up of the west of Scotland Coronary Prevention Study. N Engl J Med 2007;357:1477-1486. [PubMed: 17928595]

23. Bjerre LM, LeLorier J. Do statins cause cancer? A meta-analysis of large randomized clinical trials. Am J Med 2001;110:716-723. [PubMed: 11403756]

24. Baigent C, Keech A, Kearney PM, Blackwell L, Buck G, Pollicino C, et al. Efficacy and safety of cholesterol-lowering treatment: prospective meta-analysis of data from 90,056 participants in 14 randomised trials of statins. Lancet 2005;366:1267-1278. [PubMed: 16214597]

25. Dale KM, Coleman CI, Henyan NN, Kluger J, White CM. Statins and cancer risk: a meta-analysis. JAMA 2006;295:74-80. [PubMed: 16391219]

26. Bonovas S, Filioussi K, Tsavaris N, Sitaras NM. Use of statins and breast cancer: a meta-analysis of seven randomized clinical trials and nine observational studies. J Clin Oncol 2005;23:8606-8612. [PubMed: 16260694]

27. Bonovas S, Filioussi K, Tsavaris N, Sitaras NM. Statins and cancer risk: a literature-based metaanalysis and meta-regression analysis of 35 randomized controlled trials. J Clin Oncol 2006;24:48084817. [PubMed: 17001070]

28. Bonovas S, Filioussi K, Flordellis CS, Sitaras NM. Statins and the risk of colorectal cancer: a metaanalysis of 18 studies involving more than 1.5 million patients. J Clin Oncol 2007;25:3462-3468. [PubMed: 17687150]

29. Boudreau DM, Yu O, Miglioretti DL, Buist DS, Heckbert SR, Daling JR. Statin use and breast cancer risk in a large population-based setting. Cancer Epidemiol Biomarkers Prev 2007;16:416-421. [PubMed: 17372235]

30. Saunders, KW.; Davis, RL.; Stergachis, A. Group health cooperative. In: Strom, B., editor. Pharmacoepidemiology. John Wiley and Sons; Chichester: 2005. p. 223-239. 
31. Boudreau DM, Doescher MP, Jackson JE, Fishman PA. Impact of healthcare delivery system on where HMO-enrolled seniors purchase medications. Ann Pharmacother 2004;38:1317-1318. [PubMed: 15150379]

32. Buist DS, LaCroix AZ, Brenneman SK, Abbott T. A population-based osteoporosis screening program: who does not participate, and what are the consequences? J Am Geriatr Soc 2004;52:11301137. [PubMed: 15209651]

33. Taplin SH, Ichikawa L, Buist DS, Seger D, White E. Evaluating organized breast cancer screening implementation: the prevention of late-stage disease? Cancer Epidemiol Biomarkers Prev 2004;13:225-234. [PubMed: 14973097]

34. Washington State Department of Health, Center for Health Statistics. Washington State Vital Statistics, 2002. 2003 [Accessed 17 Sept 2004]. Available at: http://www.doh.wa.gov/ehsphl/chs/chs-data/Public/AnnSum_2002

35. Newton KM, Wagner EH, Ramsey SD, McCulloch D, Evans R, Sandhu N, et al. The use of automated data to identify complications and comorbidities of diabetes: a validation study. J Clin Epidemiol 1999;52:199-207. [PubMed: 10210237]

36. Hosmer, DW., Jr; Lemeshow, S. Applied survival analysis: regression modeling of time to event data. John Wiley \& Sons; New York: 1999.

37. Hastie, T.; Tibshirani, R.; Friedman, J., editors. The elements of statistical learning; data mining, inference, and prediction. Springer; New York: 2001.

38. Agency for Healthcare Research and Quality. The Guide to Clinical Preventive Services 2006. 2006 [Accessed 25 July 2007]. Available at: http://www.ahrq.gov/clinic/pocketgd.pdf

39. Duncan RE, El-Sohemy A, Archer MC. Statins and cancer development. Cancer Epidemiol Biomarkers Prev 2005;14:1897-1898. [PubMed: 16103434]

40. Cauley JA, McTiernan A, Rodabough RJ, LaCroix A, Bauer DC, Margolis KL, et al. Statin use and breast cancer: prospective results from the Women's Health Initiative. J Natl Cancer Inst 2006;98:700-707. [PubMed: 16705124]

41. Sprague JR, Wood ME. Statins and breast cancer prevention: time for randomized controlled trials. J Clin Oncol 2006;24:2129-2130. [PubMed: 16648518] author reply 2130-2131

42. Cyrus-David MS, Weinberg A, Thompson T, Kadmon D. The effect of statins on serum prostate specific antigen levels in a cohort of airline pilots: a preliminary report. J Urol 2005;173:1923-1925. [PubMed: 15879782]

43. Sivaprasad U, Abbas T, Dutta A. Differential efficacy of 3-hydroxy-3-methylglutaryl CoA reductase inhibitors on the cell cycle of prostate cancer cells. Mol Cancer Ther 2006;5:2310-2316. [PubMed: 16985065]

44. Platz EA. Epidemiologic musing on statin drugs in the prevention of advanced prostate cancer. Cancer Epidemiol Biomarkers Prev 2007;16:2175-2180. [PubMed: 17982117] 


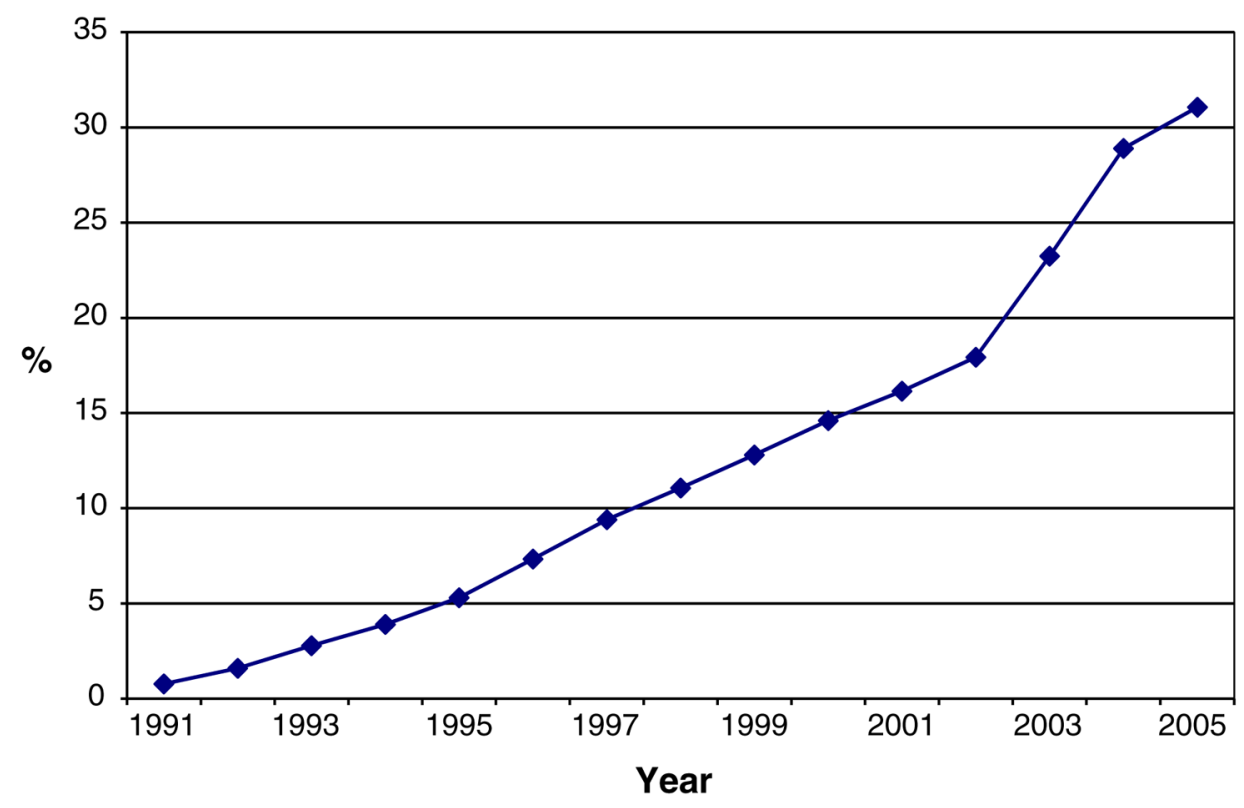

Fig. 1.

Proportion of men using statins by study year 
Boudreau et al.

Page 10

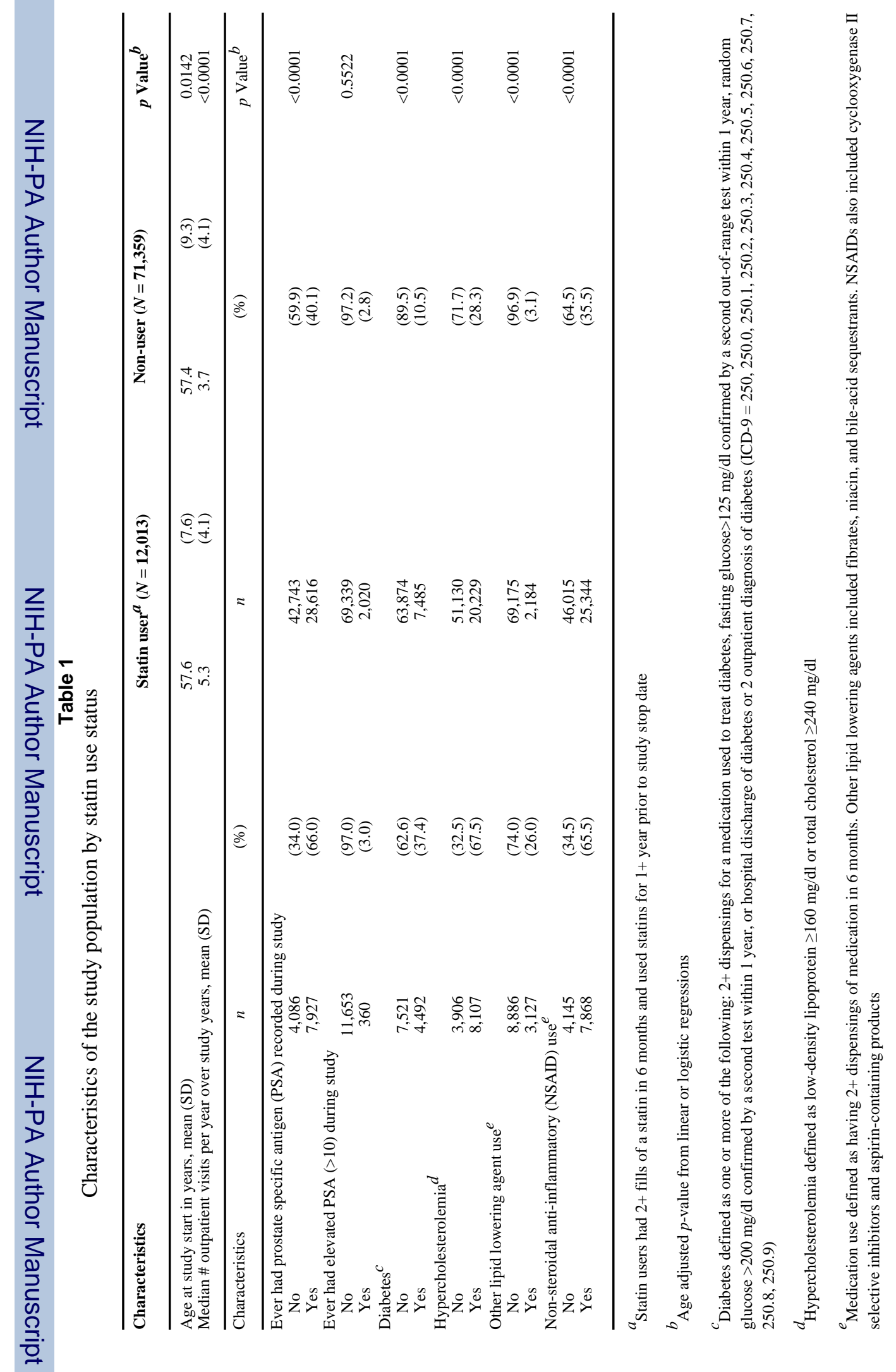

Cancer Causes Control. Author manuscript; available in PMC 2008 October 28. 
Table 2

Association between statin use and prostate cancer risk

\begin{tabular}{|c|c|c|c|c|}
\hline Statin use & No. of cases & Total person-years & $\begin{array}{l}\text { Age-adjusted HR } \\
(95 \% \text { CI })\end{array}$ & $\begin{array}{l}\text { Multivariable- } \\
\text { adjusted HR (95\% } \\
\text { CI) }{ }^{a}\end{array}$ \\
\hline All men & 2,532 & 578,885 & & \\
\hline Never & 2,286 & 533,979 & Referent & Referent \\
\hline Ever & 246 & 44,906 & $1.00(0.87-1.14)$ & $0.88(0.76-1.02)$ \\
\hline Hydrophobic only $b$ & 160 & 32,611 & $0.87(0.73-1.03)$ & $0.79(0.66-0.94)$ \\
\hline Hydrophilic only ${ }^{c}$ & 8 & 2,391 & $0.76(0.38-1.53)$ & $0.67(0.33-1.34)$ \\
\hline $\begin{array}{l}\text { Duration of use among men } \\
\text { with } 5+\text { years of data }\end{array}$ & 1,637 & 506,596 & & \\
\hline Never & 1,405 & 470,324 & Referent & Referent \\
\hline $\begin{array}{l}1-2.9 \text { years } \\
3-4.9 \text { years } \\
\text { 5+ years }\end{array}$ & $\begin{array}{l}79 \\
66 \\
87\end{array}$ & $\begin{array}{r}15,943 \\
9,844 \\
10,485\end{array}$ & $\begin{array}{l}0.77(0.62-0.97) \\
0.96(0.75-1.23) \\
1.11(0.89-1.38)\end{array}$ & $\begin{array}{l}0.75(0.59-0.95) \\
0.92(0.71-1.19) \\
1.06(0.83-1.34)\end{array}$ \\
\hline $\begin{array}{l}\text { Hydrophobic statin users } b \\
1-2.9 \text { years } \\
\text { 3-4.9 years } \\
\text { 5+ years }\end{array}$ & $\begin{array}{l}57 \\
38 \\
17\end{array}$ & $\begin{array}{r}13,250 \\
7,352 \\
5,426\end{array}$ & $\begin{array}{l}0.74(0.58-0.95) \\
0.90(0.67-1.20) \\
0.82(0.58-1.17)\end{array}$ & $\begin{array}{l}0.74(0.57-0.95) \\
0.88(0.65-1.19) \\
0.81(0.56-1.16)\end{array}$ \\
\hline
\end{tabular}

$\mathrm{HR}=$ hazard ratio and $\mathrm{CI}=$ confidence interval

${ }^{a}$ Multivariable-adjusted models include age, diabetes, hypercholesterolemia, other lipid lowering drug use, and NSAID use

${ }^{b}$ Includes users of lovastatin, simvastatin, fluvastatin, atorvastatin, and cerivastatin

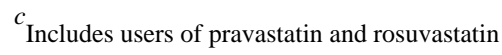

$d_{p}=0.63$ and $p=0.09$ from linear trend tests for the effect of the duration of all statin use and duration of hydrophobic statin use on prostate cancer risk 
Boudreau et al.

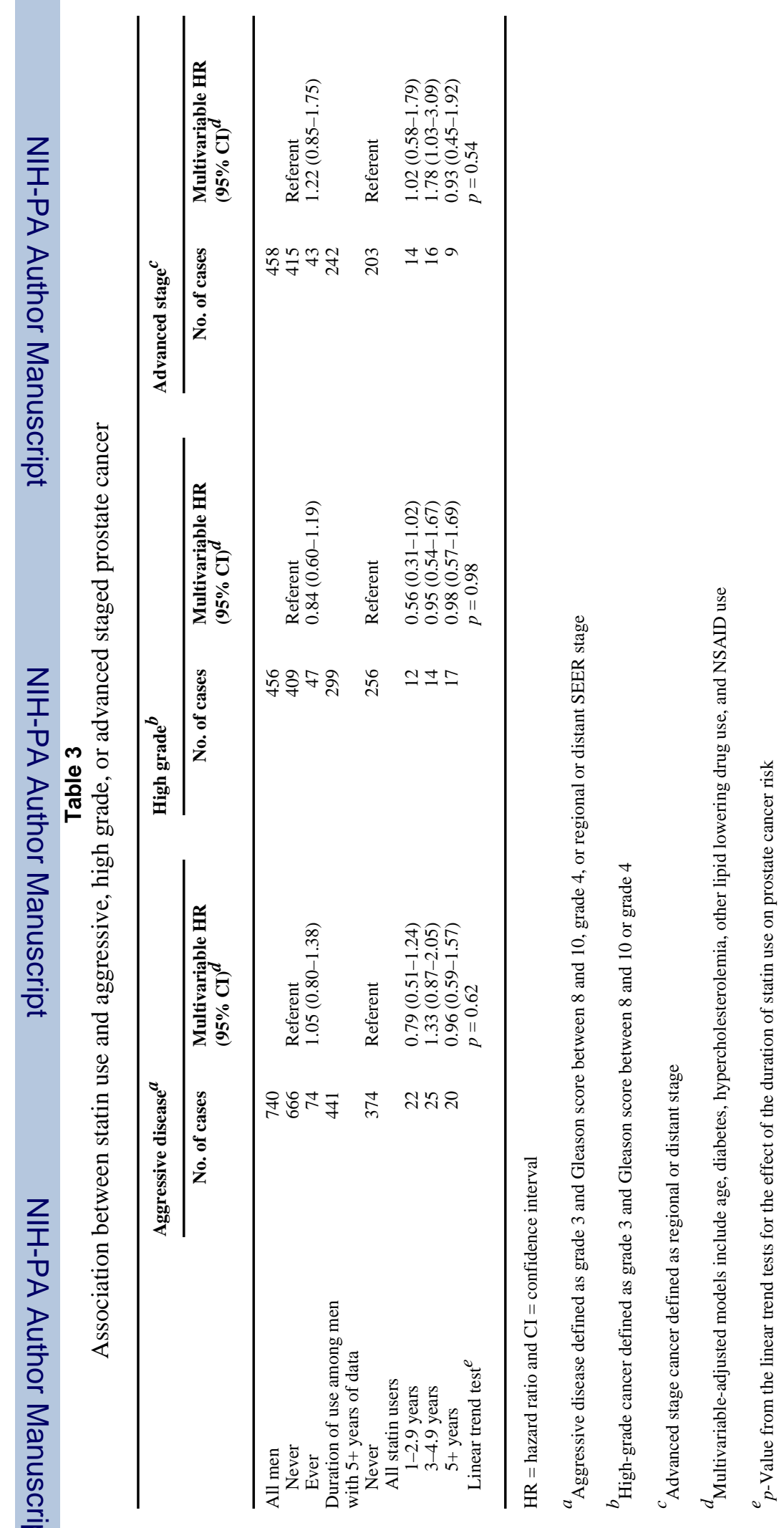

Cancer Causes Control. Author manuscript; available in PMC 2008 October 28. 